\title{
A IMPORTÂNCIA DA PREVENÇÃO DE QUEDAS EM IDOSOS
}

Poucos especialistas dão tanta importância às quedas quanto os geriatras e os gerontólogos. Certamente, veremos esse tema permear as revistas científicas da área do envelhecimento por muitos anos. Nesta edição temos a interface de estudos sobre essa morbidade.

O estudo de Pimentel e colaboradores mostra alguns resultados de uma pesquisa de base populacional realizada em 914 idosos moradores de uma grande cidade brasileira. A prevalência de quedas entre os idosos foi de $34,7 \%$ entre idosos $\geq 60$ anos e de 45,4\% naqueles com mais de 80 anos. Ou seja, reforça a importância desse problema de saúde pública e a necessidade da adoção de medidas preventivas para evitar as quedas e suas consequências, como: medo de cair, diminuição de atividade física e redução da capacidade funcional.

Sabemos ainda que a insônia e as medicações usadas para tratá-la podem aumentar o risco de quedas, especialmente no caso de medicamentos com meia-vida longa ${ }^{1}$. Scoralick e colaboradores, nesta edição, nos brindam com uma revisão sobre o recente aumento do uso de antidepressivos com efeito hipnótico para tratamento dos transtornos do sono, incluindo fármacos como mirtazapina e trazodona, pela presunção de menores efeitos colaterais, embora ainda faltem evidências sólidas sobre sua eficácia e segurança, especialmente em idosos.

Ainda nesta edição, o artigo de Matos e colaboradores, sobre dança em meio aquático, mostra alguns ganhos dessa modalidade de exercício físico, especialmente em agilidade motora, sugerindo ser essa mais uma ferramenta de reabilitação em idosos, particularmente naqueles que desenvolvem o medo de cair, já que a flutuação atuaria como suporte.

Sabemos que existem múltiplos fatores de risco para quedas em idosos (hipotensão ortostática, polifarmácia, medicações psicotrópicas, suplementação com vitamina $\mathrm{D}$, catarata, adequação de calçados e riscos ambientais, para citar alguns), sendo recomendável que as intervenções mais efetivas devem ser múltiplas e preferivelmente executadas por equipe multiprofissional. Contudo, em revisão sistemática da Cochrane ${ }^{2}$, os exercícios físicos tiveram um papel fundamental na prevenção de quedas, lesões e fraturas em idosos com quedas recorrentes. Tanto em grupo como em domicílio se recomenda exercícios supervisionados e de multicomponentes, ou seja, com foco em desafios para o equilíbrio, na melhora de força muscular e flexibilidade, especialmente em membros inferiores. Idosos com síndrome de fragilidade, condição que potencializa o risco de quedas e suas consequências, também se beneficiam de exercícios supervisionados e de multicomponentes. Binder et al. ${ }^{3}$ propuseram um treino evolutivo: a primeira fase com exercícios de flexibilidade, coordenação e equilíbrio durante três meses; uma segunda fase associando treino de força por mais três meses, aproximadamente; e, posteriormente, uma fase associando exercícios aeróbios. Essa proposta seria capaz de diminuir rapidamente o risco de quedas e melhorar em médio e longo prazo a capacidade funcional e o risco de fraturas.

\section{Alexandre Leopold Busse Editor Associado}

\section{REFERÊNCIAS}

1. Rodriguez JC, Dzierzewski JM, Alessi CA. Sleep problems in the elderly. Med Clin North Am. 2015;99(2):431-9.

2. Gillespie LD, Robertson MC, Gillespie WJ, Sherrington C, Gates S, Clemson LM, et al. Interventions for preventing falls in older people living in the community. Cochrane Database Syst Rev. 2012;9:CD007146.

3. Binder EF, Schechtman KB, Ehsani AA, Steger-May K, Brown M, Sinacore DR, et al. Effects of exercise training on frailty in community-dwelling older adults: results of a randomized, controlled trial. J Am Geriatr Soc. 2002;50(12):1921-8. 